Molecules 2001, 6, 979-987

molecules

ISSN 1420-3049

http://www.mdpi.org

\title{
Synthesis of Novel Diammonium Gemini Surfactants
}

\section{Øystein Rist, Anita Rike, Liv Ljones and Per H.J. Carlsen*}

Department of Chemistry, Norwegian University of Science and Technology, N-7491 Trondheim, Norway. Tel. +47 7359 3968, Fax +47 73594356 .

*Author to whom correspondence should be addressed; e-mail: per.carlsen@ chembio.ntnu.no

Received: 10 May 2001; in revised form 26 October 2001 / Accepted: 26 October 2001 / Published: 30

November 2001

\begin{abstract}
Selective synthesis of linear and gemini quaternary ammonium surfactants was accomplished by reacting the corresponding alkyl alcohols with 2-chloro- $N, N$-dimethylethylamine under basic conditions. The amines were quaternized with methyl chloride or methyl iodide.
\end{abstract}

Keywords. Surfactants; Synthesis; Gemini; Diamino; Cationic surfactants.

\section{Introduction}

The development of modern surfactants has been in rapid progress over the last two decades. Much effort has dealt with how their properties change with the structures of the molecules. A group of surfactants that has lately received considerable attention are molecules that contain more than one hydrophobic tail and hydrophilic heads. These are often referred to as gemini surfactants [1]. It has been established that branching of the lipophilic chain has less impact on the properties of these surfactants [2]. In addition to containing multiple heads and tails, modern surfactants also often incorporate polyether functions. This has been reported to greatly improve tolerance towards divalent cations [3]. The ether section increase the effective surface area of the ionic head group, which in turn will reduce the van der Waals interactions between the different molecules, thus physically separating the charges at the interface of the fluid [4]. 
The hydrophilic head of the surfactants may be anionic, e.g., sulfates or sulfonates, cationic or neutral. In studies related to Enhanced Oil Recovery, EOR, our group has been involved with the selective synthesis of a variety of surfactants. We here describe the selective synthesis of a series of new cationic gemini surfactants.

\section{Results and Discussion}

We report here the synthesis of a series of cationic surfactant molecules with the general structure $\mathbf{1}$ shown in Figure 1:

\section{Figure 1.}

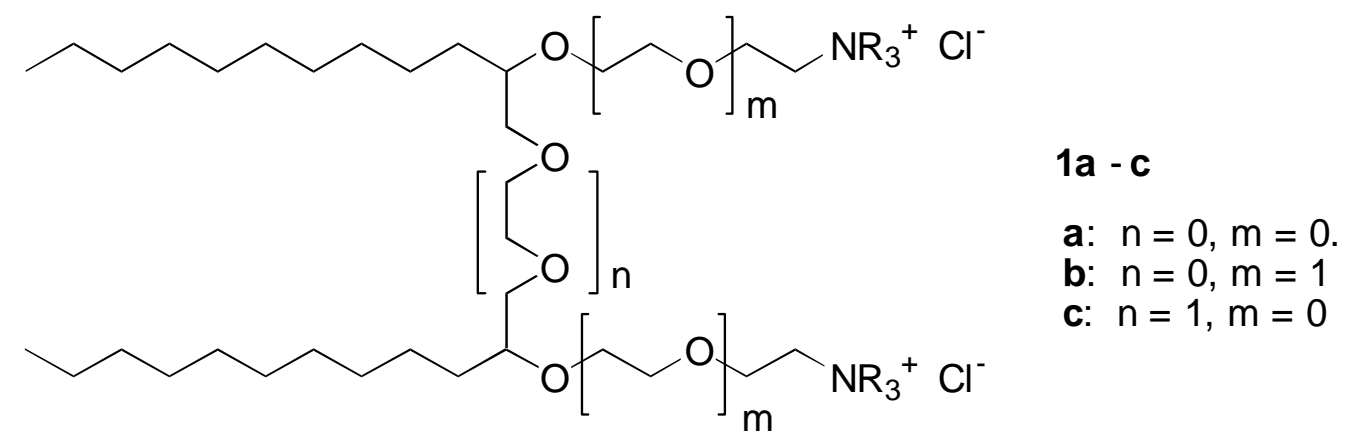

These general structures 1a-c belongs to the class of gemini surfactants. Common for products $\mathbf{1}$ is that they consist of two hydrophobic alkyl chains connected with ether spacer groups. These spacer group may contain ethyleneoxy (EO) ether groups (i.e., $\mathrm{n}=0,1$.. etc.). The hydrophilic heads consist of ethyleneamine- or the corresponding quaternary ammonium group, which is attached to the hydrophobic part of the molecule by ether bonds. The hydrophilic head may be further extended with EO-groups (i.e., $\mathrm{m}=0,1, .$.$) .$

The basic framework of molecules, 2, was constructed from the readily available 1,2-epoxydodecane (3) and 1,2-dodecanediol (4) which in the presence of a catalytic amounts of base (NaH) readily formed the lipophilic part of one target molecules, $(n=0)$. If the same transformation was carried out using 1,2-epoxydodecane and ethylene glycol the spacer sections were readily extended with one ethyleneoxy unit $(\mathrm{n}=1)$. These reactions, in general, gave the pure products in approximately $60 \%$ yields after recrystallization. The selective extension for the hydrophilic head with the EO-groups in a controlled manner was best accomplished by the reaction of the alcohol 2 with the cyclic ethylene sulfate and subsequent hydrolysis [5] yielding diol 5. These reactions were carried out as has been described earlier [6]. 


\section{Scheme 1.}
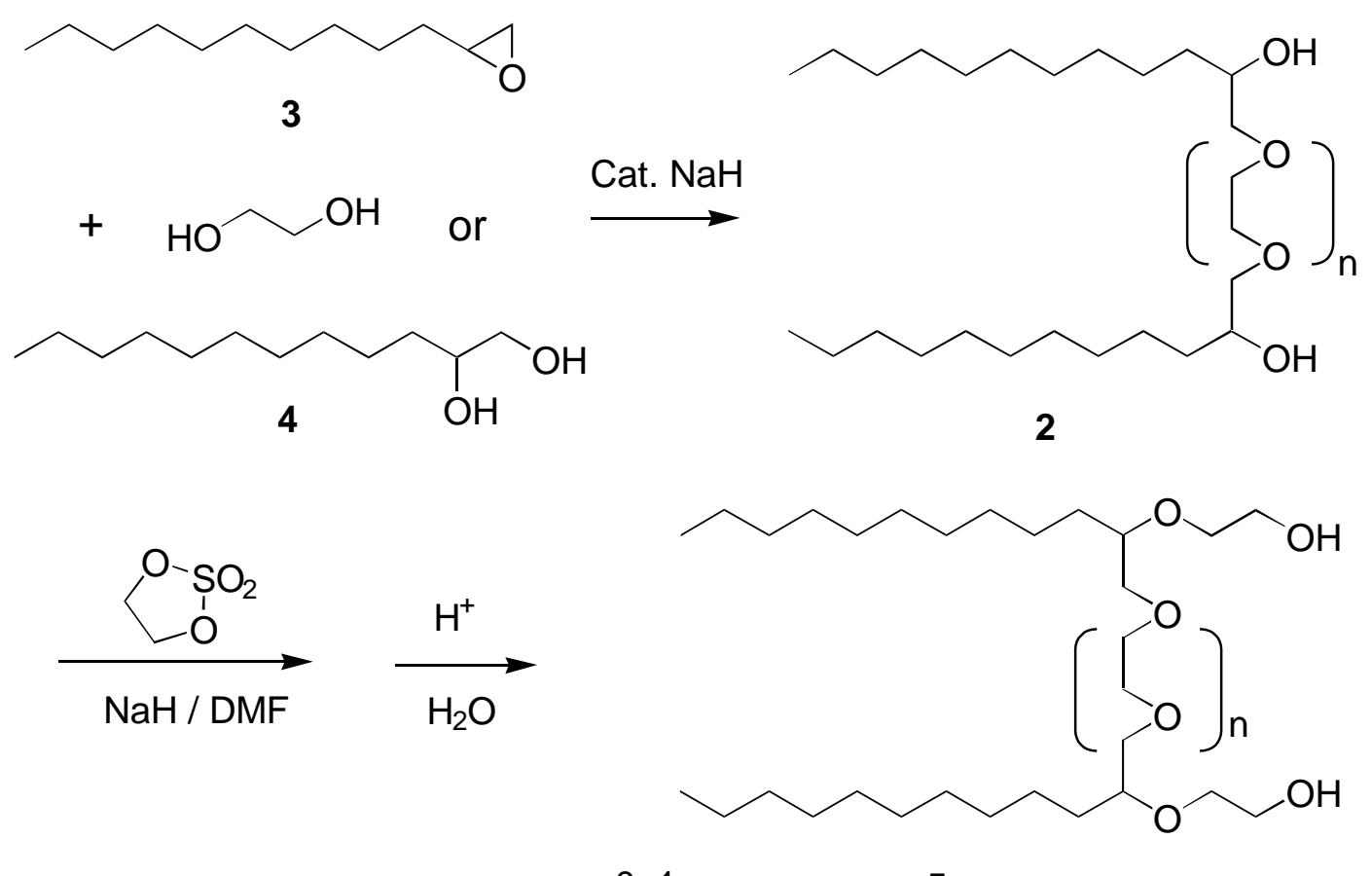

$\mathrm{n}=0,1$

5

The introduction of the ethylene amine function was furnished in a short and efficient, one step procedure in which the alcohol was reacted with 2-chloro- $N, N$-dimethylethylamine $(\mathbf{6})$ in the presence of a base, Scheme 2. This reaction was first studied for the corresponding $\mathrm{C}_{10^{-}}, \mathrm{C}_{12^{-}}$and $\mathrm{C}_{14}$-alcohols, 7a-c, and proceeds presumably through the formation of the reactive $N, N$-dimethylaziridinium ion intermediate, 8. Thus, reacting these alcohols, 7a -c, with 3 equivalents of 6 as its hydrochloride in DMF at $50{ }^{\circ} \mathrm{C}$ for 3 $\mathrm{h}$ in the presence of 7 equivalents of base $(\mathrm{NaH})$, readily afforded the desired products 9a-c in 80-90\% yields. The hydrochloride of $\mathbf{6}$ was very hygroscopic and was therefore always dried by azeotropic distillation with toluene prior to use. After extraction, products 9a -c of better than 97\% purity (GC and NMR) were routinely obtained.

\section{Scheme 2.}

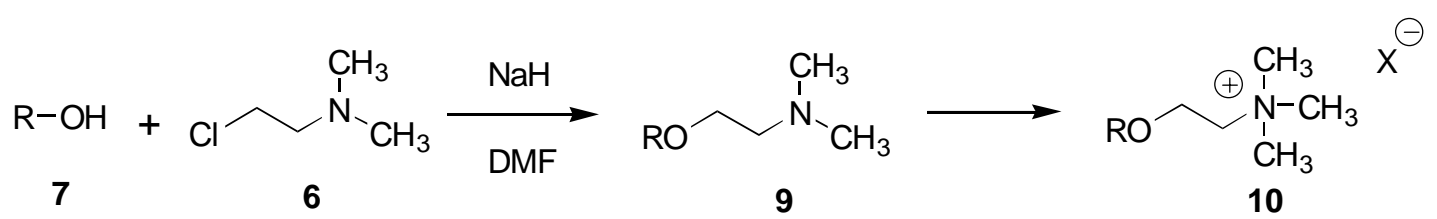

$$
\begin{aligned}
& \text { a: } R=\text { decyl } \\
& \text { b: } R=\text { dodecyl } \\
& \text { c: } R=\text { tetradecyl }
\end{aligned}
$$

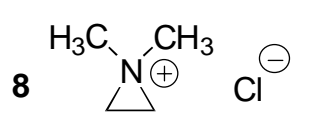


The corresponding quaternary ammonium salts, 10a-c, were easily obtained by reaction of the amines 9a -c with methyl iodide at room temperature without a solvent. The purity of the salts were generally > 95\% purity, as judged from their NMR spectra. The corresponding chlorides were obtained by reaction of the amines, 9a-c, with methyl chloride in dichloromethane at room temperature in a closed reaction flask for 2 days. These reactions were not optimized, but to ensure complete conversion 5 equivalents of the alkylating agent was used. These salts were obtained in nearly quantitative yields and were more than $95 \%$ pure by NMR.

\section{Scheme 3.}

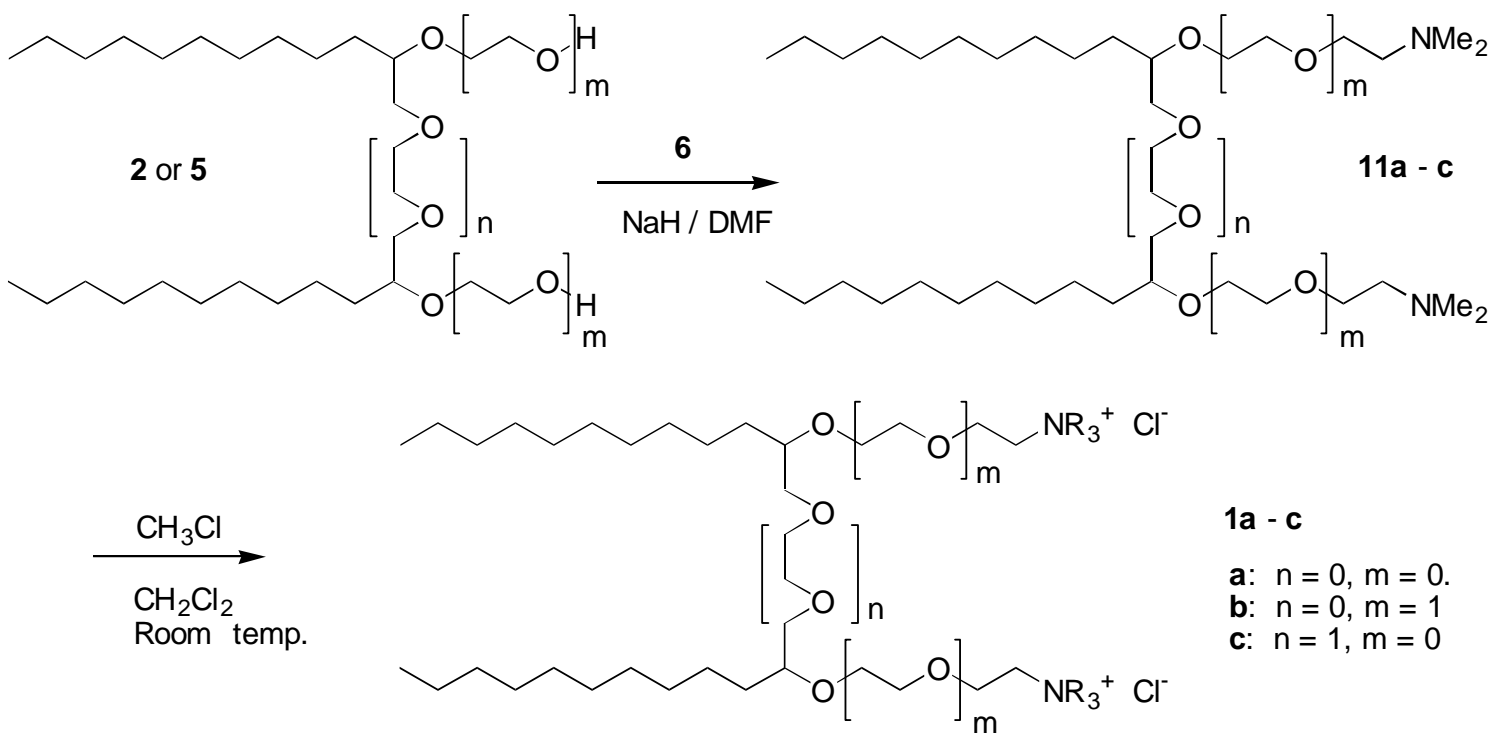

The same reaction sequence was applied on the gemini diols, 2 and $\mathbf{5}$ to synthesize the desired gemini surfactants 1a-c (Scheme 3). Due to the difficulties usually experienced when attempting to dialkylate a molecule in one step, a large excess of reagent $\mathbf{6}$ as well as base $(\mathrm{NaH})$ was applied. Attempts to reduce the excess of the reagents resulted in lower yields of the desired products. Therefore, 20 mol equivalents of $\mathrm{NaH}$ was used relative to diols 2 and 5 in DMF. The reaction mixture was heated in DMF at $50{ }^{\circ} \mathrm{C}$ for 1 $\mathrm{h}$, followed by addition of $10 \mathrm{~mol}$ equivalents of $\mathbf{6}$ as its hydrochloride. Complete conversion was obtained after 2-3 $\mathrm{h}$ as indicated by TLC analysis. The products were obtained after extraction as described above in yields ranging between 70 and 99\%. Purities of the products were all between 90 and 95\%, with DMF as the main impurity. The formation of the gemini amine surfactants 1a-c proceeded slower for the large diols (e.g., $\mathrm{n}=1, \mathrm{~m}=0$ ) than for the smaller ones. NMR analysis indicated that the degree of dialkylation in general was better than $95-98 \%$. The quarternization was carried out as described in the above. The products were obtained in 78-90\% yields. The purity of these cationic surfactants was better than $95 \%$. Flash chromatography on silica gel and ethanol as the eluent, improved the purity only slightly but also resulted in some loss of product. These reactions were not optimized. 
The NMR spectra of the single chain surfactants $\mathbf{1 0 a}-\mathbf{c}$ were recorded in $\mathrm{CDCl}_{3}$ and in $\mathrm{D}_{2} \mathrm{O}$, and were in agreement with the proposed structures. However, the NMR-spectra looked different in the two solvents. Thus, when compound $\mathbf{1 0 a}$, for example, was recorded in $\mathrm{D}_{2} \mathrm{O}$, the signals corresponding to the hydrophobic part of the molecule appeared as broad, poorly separated peaks, while the signals corresponding to the hydrophilic part displayed well resolved peaks. When the spectra were recorded in $\mathrm{CDCl}_{3}$, the signals corresponding to the hydrophobic part of the molecule were well resolved, while the signals for the hydrophilic part appeared as broad signals with poor resolution. This can be rationalized by the formation of micelles. In $\mathrm{D}_{2} \mathrm{O}$, formation of normal micelles restricts the movement of the alkyl groups in the core of the micelles, causing line broadening and poor resolution due to relaxation phenomena. The opposite was the case for the experiments in $\mathrm{CHCl}_{3}$, where formation of inverse micelles caused fewer restrictions on the movements of the alkyl groups. The ${ }^{1} \mathrm{H}-\mathrm{NMR}$ spectra were in all cases in accordance with the proposed structures $\mathbf{1 a - c}$ and 10a-c as was also the case for the ${ }^{13} \mathrm{C}-\mathrm{NMR}$ spectra of compounds 10a-c. However, ${ }^{13} \mathrm{C}-\mathrm{NMR}$ spectra are not reported for compounds $\mathbf{1 a - c}$ as no signals exceeding the noise level were recorded using standard pulse sequences. This can also explained by micelle formation and the associated relaxation phenomena. Molecules 1a-c contain two stereogenic carbon atoms, resulting in the formation of diastereomers. In the ${ }^{13} \mathrm{C}-\mathrm{NMR}$ spectrum of the precursor 11a there was indication of the two diastereomeric forms, as the signals corresponding to the stereogenic carbons were observed as double peaks. The physiochemical properties of these new surfactants are currently being investigated.

\section{Acknowledgements}

The authors wish to express their gratitude to STATOIL and the Norwegian National Research Council for financial support.

\section{Experimental}

\section{General}

All chemicals and solvents applied were of synthesis quality unless otherwise stated. The 1,2dodecanediol and 1,2-epoxydodecane were of bulk quality, (97-98\% purity). $N, N$-dimethylformamide was dried over $4 \AA$ molecular sieves. NMR-spectra were recorded (as $\mathrm{CDCl}_{3}$ solutions, unless stated otherwise) on a JEOL JNM-EX 400 FT NMR System, and Bruker Avance DPX300 or 400 instruments. IR spectra were obtained with a Nicolet 20SXC FT-IR Spectrometer. Mass spectra were obtained on a AEI MS 902 double focusing high resolution instrument equipped with electron impact ionization (EI, $70 \mathrm{eV}$ ). Melting points are uncorrected. GLC analyses were recorded on a Perkin Elmer Auto System with a Chrompack CP-5 CB column. 


\section{General Procedure for Synthesis of Monoamines (9a-c)}

Solutions of alcohols 9a-c $(0.175 \mathrm{~mol})$ in dry DMF $(200 \mathrm{~mL})$ were added under nitrogen at room temperature to sodium hydride $(1.25 \mathrm{~mol}, 30.0 \mathrm{~g})$ and dry DMF $(300 \mathrm{~mL})$ over a 30 minute period. 2-Chloro- $N, N$-dimethylethylamine hydrochloride (6) $(0.53 \mathrm{~mol} ; 76 \mathrm{~g})$, dried by azeotropic distillation with toluene and stored over phosphorus pentoxide, was then added portionwise over 60 minutes. The reaction mixture was heated at $50^{\circ} \mathrm{C}$ for 3 hours, and then quenched with ethanol $(50 \mathrm{~mL})$. The solvent was removed under reduced pressure, and the crude product then dissolved in water $(500 \mathrm{~mL})$. The aqueous phase (its pH was approximately 12) was extracted with diethyl ether (5 x $200 \mathrm{~mL}$ ). The ether phase was then extracted with $6 \mathrm{M}$ hydrochloric acid $(4 \times 30 \mathrm{~mL})$. The $\mathrm{pH}$ of the water phase was adjusted to 12-13 by adding $5 \mathrm{M}$ aqueous $\mathrm{NaOH}$ (approx.100 mL). This aqueous phase was finally extracted with ether $(4 \times 200 \mathrm{~mL})$ and the ether phase then was washed with brine $(100 \mathrm{~mL})$ and dried over anhydrous magnesium sulfate. The solvent was removed under reduced pressure to give the products.

N,N-Dimethyl-3-oxa-1-tridecylamine (9a). Obtained from 1-decanol as an oil (37 g, 92\% yield) of >98\% purity (GLC). ${ }^{1} \mathrm{H}-\mathrm{NMR}: \delta 0.88(\mathrm{t}, J=6.7 \mathrm{~Hz}, 3 \mathrm{H}), 1.26(\mathrm{~m}, 14 \mathrm{H}), 1.58(\mathrm{~m}, 2 \mathrm{H}), 2.27(\mathrm{~s}, 6 \mathrm{H}), 2.49(\mathrm{t}$, $J=5.9,2 \mathrm{H}), 3.42(\mathrm{t}, J=6.8 \mathrm{~Hz}, 2 \mathrm{H}), 3.50(\mathrm{t}, J=6.0 \mathrm{~Hz}, 2 \mathrm{H}) \mathrm{ppm} .{ }^{13} \mathrm{C}-\mathrm{NMR}: \delta 14.0,22.6,26.2,29.2$ 29.4, 29.5, 29.5, 29.6, 31.8, 45.8, 58.8, 68.8, 71.2 ppm. IR (neat): 2925, 2855, 2817, 1465, 1118, 1042 (m) $\mathrm{cm}^{-1}$. MS $\left[\mathrm{m} / \mathrm{z}\right.$ (\% rel. int.)]: $229\left(2, M^{+}\right), 58(100)$.

N,N-Dimethyl-3-oxa-1-pentadecylamine (9b). Obtained from 1-dodecane in a yield of $35.6 \mathrm{~g}(80 \%)$ and 97\% purity (GLC). ${ }^{1} \mathrm{H}-\mathrm{NMR}: \delta 0.88(\mathrm{t}, J=6.7 \mathrm{~Hz}, 3 \mathrm{H}), 1.26(\mathrm{~m}, 18 \mathrm{H}), 1.58(\mathrm{~m}, 2 \mathrm{H}), 2.27(\mathrm{~s}, 6 \mathrm{H}), 2.49(\mathrm{t}$, $J=5.9 \mathrm{~Hz}, 2 \mathrm{H}), 3.42(\mathrm{t}, J=6.8 \mathrm{~Hz}, 2 \mathrm{H}), 3.51(\mathrm{t}, J=5.9 \mathrm{~Hz}, 2 \mathrm{H}) \mathrm{ppm} .{ }^{13} \mathrm{C}-\mathrm{NMR}: \delta 14.1,22.7,26.2,29.4$, 29.5, 29.6, 29.7, 29.7, 29.7, 29.9, 31.9, 45.9, 59.0, 68.9, 71.4 ppm. IR (neat): 2925, 2854, 2817, 2768, $1465,1119,1042 \mathrm{~cm}^{-1}$. MS [m/z (\% rel. int.)]: $257\left(1.4, M^{+}\right), 58(100)$.

N,N-Dimethyl-3-oxa-1-heptadecylamine (9c). Obtained from 1-tetradecane in $41.4 \mathrm{~g}(83 \%)$ yield of $>98 \%$ purity (GLC). ${ }^{1} \mathrm{H}-\mathrm{NMR}: \delta 0.88(\mathrm{t}, J=6.7 \mathrm{~Hz}, 3 \mathrm{H}), 1.27(\mathrm{~m}, 22 \mathrm{H}), 1.57(\mathrm{~m}, 2 \mathrm{H}),, 2.26(\mathrm{~s}, 6 \mathrm{H}), 2.49(\mathrm{t}$, $J=5.9 \mathrm{~Hz}, 2 \mathrm{H}), 3.42(\mathrm{t}, J=6.8 \mathrm{~Hz}, 2 \mathrm{H}), 3.50(\mathrm{t}, J=5.9 \mathrm{~Hz}, 2 \mathrm{H}) \mathrm{ppm} .{ }^{13} \mathrm{C}-\mathrm{NMR}: \delta 14.0,22.6,26.0,29.3$, 29.4, 29.5, 29.5, 29.5, 29.5, 29.6, 29.6, 29.6, 31.8, 45.7, 58.8, 68.8, 71.2 ppm. IR (neat): 2924, 2854, 2817, $2768,1465,1119,1042 \mathrm{~cm}^{-1}$. MS [m/z (\% rel. int.)]: $285\left(1.3, M^{+}\right), 58(100)$.

General Procdure for the Synthesis of N,N,N-Trimethyl-3-oxa-1-alkylammonium halides (10a-c iodides or chlorides).

$N, N$-Dimethyl-3-oxa-1-alkylamine (approx. $50 \mathrm{mmol}$ ) was added methyl iodide (220 mmol; $15 \mathrm{~mL})$ or methyl chloride $(11 \mathrm{~g})$ in a sealed tube. The mixture was kept at room temperature for $24 \mathrm{~h}$. Pale yellow solids were formed. The products were washed with several portions of ether and then dried in vacuum. 
N,N,N-Trimethyl-3-oxa-1-tridecylammonium iodide (10a-iodide). Obtained in $96 \%$ yield and > 98\% purity (by $\left.{ }^{1} \mathrm{H}-\mathrm{NMR}\right) .{ }^{1} \mathrm{H}-\mathrm{NMR}: \delta 0.88(\mathrm{t}, J=6.7 \mathrm{~Hz}, 3 \mathrm{H}), 1.26(\mathrm{~m}, 14 \mathrm{H}), 1.58(\mathrm{~m}, 2 \mathrm{H}), 3.48(\mathrm{~m}, 2 \mathrm{H}), 3.50$ (s, 9H), 3.90 (m, 2H), 3.97 (m, 2H) ppm. ${ }^{13} \mathrm{C}-\mathrm{NMR}: \delta$ 14.2, 22.8, 26.3, 29.4, 29.5, 29.5, 29.7, 29.7, 32.0, 55.1, 64.9, 66.1, 72.1 ppm. IR (KBr): 2916, 2850, 1478, 1370, 1139, 1120, 1056, 955, $877 \mathrm{~cm}^{-1}$.

N,N,N-Trimethyl-3-oxa-1-pentadecylammonium iodide (10b-iodide). Obtained in $96 \%$ yield and $>98 \%$ purity $\left({ }^{1} \mathrm{H}-\mathrm{NMR}\right) .{ }^{1} \mathrm{H}-\mathrm{NMR}: \delta 0.88(\mathrm{t}, J=6.7 \mathrm{~Hz}, 3 \mathrm{H}), 1.26(\mathrm{~m}, 18 \mathrm{H}), 1.57(\mathrm{~m}, 2 \mathrm{H}), 3.48(\mathrm{~m}, 2 \mathrm{H}), 3.49$ (s, 9H) $3.91(\mathrm{~m}, 2 \mathrm{H}), 3.98(\mathrm{~m}, 2 \mathrm{H}) \mathrm{ppm} .{ }^{13} \mathrm{C}-\mathrm{NMR}: \delta 14.3,22.9,26.3,29.5,29.6,29.6,29.7,29.8,29.8,29.9$, 32.1, 55.1, 64.9, 66.1, 72.1 ppm. IR (KBr): 2917, 2849, 1466, 1140, 1120, 954, 866, $720 \mathrm{~cm}^{-1}$.

N,N,N-Trimethyl-3-oxa-1-heptadecylammonium iodide (10c-iodide). Obtained in $90 \%$ yield and $>98 \%$ purity (by $\left.{ }^{1} \mathrm{H}-\mathrm{NMR}\right) .{ }^{1} \mathrm{H}-\mathrm{NMR}: \delta 0.88(\mathrm{t}, J=7 \mathrm{~Hz}, 3 \mathrm{H}), 1.26(\mathrm{~m}, 22 \mathrm{H}), 1.56(\mathrm{~m}, 2 \mathrm{H}), 3.49(\mathrm{t}, J=6.6 \mathrm{~Hz}$, $2 \mathrm{H}), 3.52(\mathrm{~s}, 9 \mathrm{H}) 3.91(\mathrm{~s}, 2 \mathrm{H}), 3.97(\mathrm{~m}, 2 \mathrm{H}) \mathrm{ppm} .{ }^{13} \mathrm{C}-\mathrm{NMR}: \delta 14.3,22.9,26.3,29.5,29.6,29.6,29.7$, 29.8, 29.8, 29.8, 29.9, 29.9, 32.1, 55.2, 64.9, 66.1, 72.2 ppm. IR (KBr): 2917, 2849, 1468, 1400, 1139, $1120,1054,954,879,721 \mathrm{~cm}^{-1}$.

$N, N, N$-Trimethyl-3-oxa-1-tridecylammonium chloride (10a-chloride). Obtained in $96 \%$ yield and $>98 \%$ purity (by $\left.{ }^{1} \mathrm{H}-\mathrm{NMR}\right) .{ }^{1} \mathrm{H}-\mathrm{NMR}: \delta 0.88(\mathrm{t}, J=6.8 \mathrm{~Hz}, 3 \mathrm{H}), 1.26(\mathrm{~m}, 14 \mathrm{H}), 1.58(\mathrm{~m}, 2 \mathrm{H}), 3.47$ (t, $J=6.6 \mathrm{~Hz}, 2 \mathrm{H}), 3.50(\mathrm{~s}, 9 \mathrm{H}), 3.88(\mathrm{~m}, 2 \mathrm{H}), 4.00(\mathrm{~m}, 2 \mathrm{H}) \mathrm{ppm} .{ }^{13} \mathrm{C}-\mathrm{NMR}: \delta 14.5,23.0,26.5,29.6,29.7$, 29.8, 29.9, 29.9, 32.2, 54.8, 65.2, 66.0, 72.2 ppm. IR (KBr): 2958, 2916, 2851, 1483, 1418, 1370, 1156, $1124,1073,987,965,880,719 \mathrm{~cm}^{-1}$.

N,N,N-Trimethyl-3-oxa-1-pentadecylammonium chloride (10b-chloride). Obtained in 90\% yield and $>98 \%$ purity (by $\left.{ }^{1} \mathrm{H}-\mathrm{NMR}\right) .{ }^{1} \mathrm{H}-\mathrm{NMR}: \delta 0.84(\mathrm{t}, J=6.7 \mathrm{~Hz}, 3 \mathrm{H}), 1.22(\mathrm{~m}, 18 \mathrm{H}), 1.51(\mathrm{~m}, 2 \mathrm{H}), 3.43(\mathrm{t}$, $J=6.6 \mathrm{~Hz}, 2 \mathrm{H}), 3.46(\mathrm{~s}, 9 \mathrm{H}) 3.84(\mathrm{~s}, 2 \mathrm{H}), 3.95(\mathrm{~m}, 2 \mathrm{H}) \mathrm{ppm} .{ }^{13} \mathrm{C}-\mathrm{NMR}: \delta 14.3,22.8,26.3,29.5,29.5$, 29.6, 29.7, 29.8, 29.8, 29.8, 32.1, 54.7, 65.0, 65.8, 72.0 ppm. IR (KBr): 2957, 2916, 2851, 1470, 1418, $1370,1123,1072,961,879,719 \mathrm{~cm}^{-1}$.

$N, N, N$-Trimethyl-3-oxa-1-heptadecylammonium chloride (10c-chloride). Obtained in $95 \%$ yield and $>98 \%$ purity (by $\left.{ }^{1} \mathrm{H}-\mathrm{NMR}\right) .{ }^{1} \mathrm{H}-\mathrm{NMR}: \delta 0.88(\mathrm{t}, J=6.8 \mathrm{~Hz}, 3 \mathrm{H}), 1.26(\mathrm{~m}, 22 \mathrm{H}), 1.56(\mathrm{~m}, 2 \mathrm{H}), 3.47(\mathrm{~m}, 2 \mathrm{H}), 3.48$ (s, 9H), $3.89(\mathrm{~m}, 2 \mathrm{H}), 4.00(\mathrm{~m}, 2 \mathrm{H}) \mathrm{ppm} .{ }^{13} \mathrm{C}-\mathrm{NMR}: \delta$ 14.3, 22.9, 26.4, 29.6, 29.6, 29.6, 29.7, 29.8, 29.8, 29.9, 29.9, 29.9 32.1, 54.7, 65.0, 65.8, 72.1 ppm. IR (KBr): 2958, 2916, 2850, 1484, 1470, 1419, 1394, $1157,1124,1087,1072,1007,966,880,718 \mathrm{~cm}^{-1}$.

General Procedure for the Synthesis of diamines (11a-c).

The diol 2 and 5 (25 mmol) were dried by azeotropic distillation with toluene before use. The diol was then dissolved in dry DMF $(300 \mathrm{~mL})$. The reaction was heated at $50^{\circ} \mathrm{C}$, sodium hydride $(12.4 \mathrm{~g}$, $517 \mathrm{mmol}$ ) was added slowly and the reaction was stirred for 1 hour. Dry 2-chloro- $N, N$-dimethyl- 
ethylamine hydrochloride $(37.0 \mathrm{~g}, 257 \mathrm{mmol})$ was then added and the reaction mixture stirred for 3 hours. After cooling to room ethanol $(100 \mathrm{~mL})$ was added. The solvent was removed by evaporation under reduced pressure, and water $(300 \mathrm{~mL})$ was added. The $\mathrm{pH}$ of the aqueous phase was adjusted to $12-13$, and it was then extracted with dichloromethane $(6 \times 50 \mathrm{~mL})$. The organic phase was extracted with $1 \mathrm{M}$ hydrochloric acid $(3 \times 50 \mathrm{~mL})$. The $\mathrm{pH}$ of the aqueous phase was adjusted to $12-13$ with $5 \mathrm{M}$ sodium hydroxide $(50 \mathrm{~mL})$ and was then extracted with dichloromethane $(5 \times 50 \mathrm{~mL})$. The organic phase was dried over $\mathrm{MgSO}_{4}$, filtered and concentrated under reduced pressure.

$N, N, N^{\prime}, N^{\prime}$-Tetramethyl-4,8-didecyl-3,6,9-trioxa-1,11-undecanediamine (11a). Obtained from 13-oxa11,15-pentacosanediol (2a), and isolated as an oil in quantitative yield (104\%) and 95\% purity (GLC). ${ }^{1} \mathrm{H}-\mathrm{NMR}: \delta 0.88(\mathrm{t}, J=6.7 \mathrm{~Hz}, 6 \mathrm{H}), 1.26-1.48(\mathrm{~m}, 36 \mathrm{H}), 2.27(\mathrm{~s}, 12 \mathrm{H}), 2.50(\mathrm{~m}, 4 \mathrm{H}), 3.37-3.84(\mathrm{~m}, 10 \mathrm{H})$ ppm. ${ }^{13} \mathrm{C}-\mathrm{NMR}: \delta$ 14.5, 23.0, 26.0, 29.7, 30.0, 30.0, 30.1, 30.1, 32.2, 32.3, 45.9, 59.4, 68.0, 74.4, 74.5 (two diastereomers), 79.5, 79.6 (two diastereomers) ppm. IR (neat): 2925, 2854, 2817, 2768, 1460, 1117 $\mathrm{cm}^{-1}$. MS [m/z (\% rel. int.)]: $529(M+1,0.2), 528\left(0.5, M^{+}\right), 527(1, M-1), 458(8), 73$ (22), 72 (40), 71 (24), 58 (100).

$N, N, N$ ',N'-Tetramethyl-7,11-didecyl-3,6,9,12,15-pentaoxa-1,17-heptadecanediamine (11b). Obtained from 4,8-didecyl-3,6,9-trioxa-1,11-undecanediol (5) in 98\% yield and 88\% purity (GLC). ${ }^{1} \mathrm{H}-\mathrm{NMR}: \delta 0.88(\mathrm{t}$, $J=6.8 \mathrm{~Hz}, 6 \mathrm{H}), 1.26(\mathrm{~m}, 32 \mathrm{H}), 1.46(\mathrm{~m}, 4 \mathrm{H}), 2.36+2.42(\mathrm{~s}, 12 \mathrm{H}), 2.65(\mathrm{~m}, 4 \mathrm{H}), 3.39-3.55(\mathrm{~m}, 8 \mathrm{H}), 3.59-$ $3.70(\mathrm{~m}, 8 \mathrm{H}), 3.76-3.81(\mathrm{~m}, 2 \mathrm{H}) \mathrm{ppm} .{ }^{13} \mathrm{C}-\mathrm{NMR}: \delta$ 14.5, 23.0, 25.9, 29.7 29.9, 29.9, 30.0, 30.1, 32.2, 32.3, 46.0, 59.4, 68.1, 69.2, 71.1, 74.4, 79.6 ppm. IR (neat): 2924, 2854, 2769, 1676, 1461, 1384, 1263, 1121, $963,732 \mathrm{~cm}^{-1} . \mathrm{MS}\left[\mathrm{m} / z\right.$ (\% rel. int.)]: $616\left(1, \mathbf{M}^{+}\right), 615$ (4, M-1), 116 (13), $72(28), 71$ (22), 58 (100).

$N, N, N^{\prime}, N^{\prime},-$ Tetramethyl-4,11-didecyl-3,6,9,12-tetraoxa-1,14-tetradecanediamine (11c). Obtained from 13,16-dioxa-11,18-octacosanediol (2c) in 80\% yield and 95\% purity. ${ }^{1} \mathrm{H}-\mathrm{NMR}: \delta 0.88(\mathrm{t}, J=6.8 \mathrm{~Hz}, 6 \mathrm{H})$, $1.26(\mathrm{~m}, 32 \mathrm{H}), 1.46(\mathrm{~m}, 4 \mathrm{H}), 2.36+2.39(\mathrm{~s}, 12 \mathrm{H}), 2.65(\mathrm{~m}, 4 \mathrm{H}), 3.39-3.52(\mathrm{~m}, 6 \mathrm{H}), 3.59-3.67(\mathrm{~m}, 6 \mathrm{H})$, 3.77-3.81 (m, 2H) ppm. ${ }^{13} \mathrm{C}-\mathrm{NMR}: \delta$ 14.5, 23.0, 25.9, 29.7, 29.9, 30.0, 30.0, 30.0, 30.1, 32.3, 46.0, 59.4, 68.1, 71.1, 74.4, 79.6 ppm. IR (neat): 2925, 2854, 2817, 2768, 1684, 1462, 1116, $1049 \mathrm{~cm}^{-1} . \mathrm{MS}[\mathrm{m} / z(\%$ rel. int.)]: $572\left(0.4, M^{+}\right), 571(1 M-1), 73(19), 72(33), 17(16), 58(100)$.

4,8-Didecyl-3,6,9-trioxa-undecane-1,11-di(trimethylammonium) dichloride (1a). Prepared from 11a as described above and obtained in $82 \%$ yield and $96 \%$ purity (by ${ }^{1} \mathrm{H}-\mathrm{NMR}$ ). A sample was purified by flash chromatography $\left(\mathrm{SiO}_{2} / \mathrm{ethanol}\right)$ gave a yield of $44 \%$ of product of $>99 \%$ purity (by $\left.{ }^{1} \mathrm{H}-\mathrm{NMR}\right) .{ }^{1} \mathrm{H}-\mathrm{NMR}$ $\left(\mathrm{D}_{2} \mathrm{O}\right): \delta 0.85(\mathrm{t}, J=6.7 \mathrm{~Hz}, 6 \mathrm{H}), 1.27(\mathrm{~m}, 32 \mathrm{H}), 1.53(\mathrm{~m}, 4 \mathrm{H}), 3.19(\mathrm{~s}, 18 \mathrm{H}), 3.28-3.30(\mathrm{~m}, 2 \mathrm{H}), 3.37-3.72$ (m, 16H), 3.95-4.04 (m, 4H) ppm. IR (neat): 2954, 2922, 2853, 1480, 1467, 1415, 1378, 1345, 1271, $1244,1188,1119,955,877,831 \mathrm{~cm}^{-1}$.

7,11-Didecyl-3,6,9,12,15-pentaoxa-heptadecane-1,17-di(trimethylammonium) dichloride (1b). Obtained from $11 b$ in $93 \%$ yield and $>96 \%$ purity. ${ }^{1} \mathrm{H}-\mathrm{NMR}\left(\mathrm{D}_{2} \mathrm{O}\right): \delta 0.87(\mathrm{t}, J=6.8 \mathrm{~Hz}, 6 \mathrm{H}), 1.28(\mathrm{~m}, 32 \mathrm{H}), 1.58$ 
(m, 4H), $3.21(\mathrm{~s}, 18 \mathrm{H}), 3.30-3.33(\mathrm{~m}, 2 \mathrm{H}), 3.47-3.69(\mathrm{~m}, 8 \mathrm{H}), 3.96-4.08(\mathrm{~m}, 4 \mathrm{H}) \mathrm{ppm}$. IR (neat): 2953, 2924, 2853, 1471, 1462, 1116, 950, $876 \mathrm{~cm}^{-1}$.

4,11-Didecyl-3,6,9,12-tetraoxa-tetradecane-1,14-di(trimethylammonium) dichloride (1c). Obtained from 11c in $78 \%$ yield and $90 \%$ purity. Flash-chromatography $\left(\mathrm{SiO}_{2} /\right.$ ethanol) gave the product in $40 \%$ yield and $>96 \%$ (+ 4\% ethanol) (by $\left.{ }^{1} \mathrm{H}-\mathrm{NMR}\right) .{ }^{1} \mathrm{H}-\mathrm{NMR}\left(\mathrm{D}_{2} \mathrm{O}\right): \delta 0.85(\mathrm{t}, J=6.8 \mathrm{~Hz}, 6 \mathrm{H}), 1.26(\mathrm{~m}, 32 \mathrm{H}), 1.53$ (m, 4H), $3.19(\mathrm{~s}, 18 \mathrm{H}), 3.29-3.30(\mathrm{~m}, 2 \mathrm{H}), 3.36-3.64(\mathrm{~m}, 12 \mathrm{H}), 3.94-4.02$ (m, 4H) ppm. IR (neat): 2955, $2923,2853,1471,1116,957,878,721 \mathrm{~cm}^{-1}$.

\section{References}

1. (a) Bunton. C.A., Robinson, L., Schaak, J., Stam. M.F. J. Org. Chem. 1971, 36, 2346; (b) Masuyama, A., Sumida, Y., Zhu, Y.-P. J. Jpn. Oil Chem. Soc. 1988, 37, 746; (c) Zhu, Y.-P., Masuyama, A., Okahara, M. J. Am. Oil Chem. Soc. 1990, 67, 459; (d) Zhu, Y.-P., Masuyama, A., Kirito, Y.-I., Okahara, M., Rosen, M.J. J. Am. Oil Chem. Soc. 1992, 69, 626; (e) Zhu, Y.-P., Masuyama, A., Nagata, T., Okahara, M. J. Jpn. Oil Chem. Soc. 1991, 40, 473; (f) Zhu, Y.-P., Masuyama, A., Kirito, Y.-I., Okahara, M. J. Am. Oil Chem. Soc. 1991, 68, 539; (g) Masuyama, A., Hirino, T, Zhu, Y.-P., Okahara, M., Rosen, M.J. J. Jap.Oil Chem. Soc. 1992, 41, 301; (h) Masuyama, A., Masatoshi, Y., Zhu, Y.-P., Toshiyuki, K. Nakatsuji. J. Chem. Soc.Chem. Commun. 1994, 1435; (i) Zhu, Y.-P., Masuyama, A., Okahara, M. J. Am. Oil Chem. Soc. 1991, 68, 268; (j) Zhu, Y.-P., Masuyama, A., Kobata, Y., Nakatsuji, Y., Okahara, M., Rosen, M.J. J. Coll. and Interfac. Sci. 1993, 158, 40; (k) Kim, T.-S., Kida, T., Nakatsuji, Y., Hirao, T., Ikeda, I. J. Am. Oil Chem. Soc. 1996, 73, 907; (1) Rosen, M.J., Letian, L. J. Am. Oil Chem. Soc. 1996, 73, 885; (m) Menger, F.M., Littau, C.A., J. Am. Chem. Soc. 1991, 113, 1451; (n) Sommerdijk, N.A.J.M., Hoeks, T.H.L., Synak, M., Feiters, M.C., Nolte, R.J.M., Zwanenburg, B. J. Am. Chem. Soc. 1997, 119, 4338; (o) Myers, D., Surfactant Science and Technology, $2^{\text {nd }}$ ed., VCH: New York, 1992.

2. Zana, R. Surfactant Science 1996, 1, 566.

3. Rosen, J.M., Zhu, Y.-P., Morrall, S.W. J. Chem. Eng. Data 1996, 41, 1160.

4. Gilje, E., Maldal, T., Preceedings of the Third Symposium on Mining Chemistry, Siofok, Hungary, 1990, p 157.

5. Gautun, O.R., Carlsen, P.H.J., Maldahl, T., Vikane, O., Gilje, E. Acta Chem. Scand. 1996, 50, 170.

6. Rist, Ø., Carlsen, P.H.J., Synth. Commun. 1998, 29, 749.

Sample Availability: Available from the authors.

(C) 2001 by MDPI (http://www.mdpi.org). Reproduction is permitted for noncommercial purposes. 